\title{
PROFIL KOSAKATA PADA BUKU BACAAN CERITA RAKYAT TINGKAT SD DI PULAU JAWA, KALIMANTAN, DAN SULAWESI
}

\author{
Intan Amalia \\ intanamalia1312@gmail.com \\ Universitas Airlangga
}

\begin{abstract}
The folklore literacy reading material books are the books selected and recommended by the government which have the good quality since they are suitable for the readers' need. This study attempts to discover the vocabulary profile in the folklore literacy reading material books for elementary students in Java, Kalimantan, and Sulawesi by searching for the lexical variation and observing the readability level in the folklore books of the respective islands. Moreover, this study also attempts to reveal the similarities and differences among the folklore in Java, Kalimantan, and Sulawesi. The lexical variation of Javanese folklore is the lowest, that is 0.074. The folklore books of Kalimantan is the easiest to read since they contain more common Indonesian vocabulary, that is $62.09 \%$, than Javanese and Sulawesi folklore books. The folklore in Java, Kalimantan, and Sulawesi generally employs the characters of king and society as the influencing figures in all folklore with the setting of kingdom and day as the most common unit of time and place. The folklore in Java specifically depicts the forest ecology and highly demonstrates the social culture which comprises occupation and entertainment. The folklore in Kalimantan specifically predominates the river ecology and village as the material culture. The folklore in Sulawesi specifically presents the marine ecology with fish as the fauna that can be easily encountered in Sulawesi people's daily life.
\end{abstract}

Keywords: folklore, vocabulary profile, readability level, lexical variation

\begin{abstract}
Abstrak
Buku bahan bacaan literasi cerita rakyat adalah buku-buku yang dipilih dan direkomendasikan oleh pemerintah yang berarti memiliki kualitas yang baik karena sesuai dengan tingkat kebutuhan pembacanya. Penelitian ini bertujuan untuk mengetahui profil kosakata dalam bahan bacaan literasi cerita rakyat tingkat SD di Pulau Jawa, Kalimantan, dan Sulawesi dengan mencari variasi leksikal serta melihat tingkat kemudahan pada buku cerita rakyat di masing-masing pulau. Selain itu, penelitian ini juga akan memaparkan persamaan dan perbedaan antara cerita rakyat di Pulau Jawa, Kalimantan, dan Sulawesi. Variasi leksikal pada cerita rakyat di Pulau Jawa memiliki variasi leksikal yang paling kecil yaitu 0,074. Buku cerita rakyat di Pulau Kalimantan adalah buku yang paling mudah dibaca karena mengandung kosakata umum Bahasa Indonesia yang lebih banyak yaitu 62,09\% dari pada buku cerita anak di Pulau Jawa dan Sulawesi. Secara umum cerita rakyat di Pulau Jawa, Kalimantan, dan Sulawesi menggunakan tokoh raja dan rakyat sebagai tokoh yang berpengaruh dalam semua cerita rakyat dengan latar kerajaan dan satuan waktu yang paling sering digunakan adalah hari. Cerita rakyat di Pulau Jawa secara khusus menunjukkan ekologi hutan dan sangat menunjukkan kebudayaan sosialnya yang mencakup pekerjaan dan hiburan. Cerita rakyat di Pulau Kalimantan secara khusus menonjolkan ekologi sungai dan kebudayaan material yaitu kampung. Cerita rakyat di Pulau Sulawesi secara khusus lebih menunjukkan ekologi yang dimilikinya yaitu laut dan ikan sebagai fauna yang mudah ditemukan dalam kehidupan sehari-hari masyarakat Sulawesi.
\end{abstract}

Kata Kunci: cerita rakyat, profil kosakata, tingkat kemudahan, variasi leksikal 


\section{PENDAHULUAN}

Setiap daerah memiliki cerita rakyat yang berbeda-beda dengan ciri khas dan keunikan budayanya masing-masing. Cerita rakyat menurut Mustakim (2005) yaitu cerita yang disampaikan secara lisan dari generasi ke generasi lainnya yang tidak diketahui nama pengarangnya. Menurut Bascom (Danandjaja, 2007) cerita rakyat dapat dikategorikan dalam tiga kategori besar yaitu mite, legenda, dan dongeng. Mite adalah cerita rakyat yang dipercaya pernah terjadi dan dianggap keramat oleh masyarakat. Legenda adalah prosa rakyat yang dianggap benar-benar terjadi pada masa lampau, tetapi masyarakat tidak menganggap suci ataupun mengeramatkannya. Sedangkan dongeng yaitu cerita prosa rakyat yang tidak dianggap benar-benar terjadi oleh masyarakatnya. Cerita rakyat biasanya memiliki pesan atau nasihat yang disampaikan secara tidak langsung bagi masyarakat lokal. Walaupun cerita rakyat memiliki beberapa variasi karena sifatnya yang diturunkan melalui lisan, pesan dalam cerita selalu merujuk pada hal yang sama. Pesan moral pada cerita rakyat yang disampaikan dapat berkaitan dengan hubungan kepada Tuhan, diri sendiri, sesama manusia, alam, ataupun kebangsaan. Dalwiningsih (2017) menyebutkan bahwa isi atau pesan cerita yang ada dalam cerita rakyat dapat dijadikan sebagai sarana untuk pembelajaran budi pekerti. Oleh karena itu cerita rakyat biasanya diceritakan kembali kepada anak-anak sebagai media pembelajaran sekaligus hiburan.

Buku-buku cerita rakyat dengan berbagai versi mudah sekali ditemukan, tetapi tidak semua buku tersebut sesuai dan menarik bagi pembacanya. Bentuk buku cerita rakyat, baik dari kebahasaan hingga model penyampaian cerita dapat mempengaruhi pembacanya. Oleh karena itu memilih buku cerita rakyat yang tepat untuk anak adalah salah satu hal yang diperlukan dalam pendidikan berbasis budaya lokal sekaligus melestarikan budaya lokal yang positif. Sarana kebahasaan cerita untuk anak harus disesuaikan dengan tahap perkembangan bahasa anak seperti berisi kata-kata yang umum dan penggunaan kalimat yang sederhana sehingga mudah dicerna dan diingat anak. Ini merupakan salah satu tantangan bagi pendidik maupun orang tua untuk dapat memilih bahan bacaan untuk anak yang sesuai dengan tahap perkembangan anak tersebut. Cahyaningrum, Cholimah, \& Christianti (2014) mengadakan penelitian dengan melakukan pelatihan pengenalan karakter dan meningkatkan keterampilan bercerita untuk anak usia dini melalui cerita rakyat bagi pendidik PAUD. Hasil menunjukkan bahwa pelatihan sejenis ini efektif dalam meningkatkan pemahaman dan keterampilan bercerita bagi pendidik PAUD. Penelitian ini menunjukkan bahwa pengetahuan tentang strategi pengajaran melalui cerita rakyat termasuk memilih bahan bacaan cerita yang tepat adalah hal yang diperlukan agar isi dan pesan dalam cerita dapat disampaikan kepada anak-anak sebagai pembelajaran yang menarik dan efektif.

Salah satu cara yang dapat digunakan untuk melihat kebahasaan suatu teks adalah dengan melihat profil kosakatanya. Kosakata sendirimerupakan daftarkata yang terdapat 
dalam sebuah bahasa yang disepakati dan dipergunakan oleh sekelompok masyarakat tutur dalamberkomunikasi (Rhubido, 2017). Nation(2001) mengklasifikasikankosakata menjadi (1) kosakata frekuensi tinggi (high frequency vocabulary) yaitu kosakata yang paling sering ditemui dalam teks. (2) Kosakata akademik (academic vocabulary) yaitu kosakata yang digunakan dan ditemukan pada teks-teks akademik. (3) Kosakata teknik (technical vocabulary) yaitu kosakata yang secara spesifik dan khas dipakai di ranah tertentu. Dan (4) kosakata frekuensi rendah (low-frequency vocabulary) yaitu kosakata yang jarang digunakan dalam teks sehingga cakupan kemunculan kata sangat kecil. Banyak temuan dalam kosakata bahasa Inggris mengenai daftar kosakata umum, tetapi daftar kosakata umum Bahasa Indonesia hanya pernah dilakukan oleh Kwary (2013).

Untuk melihat kualitas suatu teks juga dapat dilakukan dengan melihat variasi leksikalnya (lexical diversity). Semakin bervariasi kosakata yang dimiliki suatu teks, semakin tinggi variasi leksikalnya. Agar leksikal teks menjadi sangat beragam, pembicara atau penulis harus menggunakan banyak kata yang berbeda, dengan sedikit pengulangan kata-kata yang sudah digunakan (Johansson, 2009). Dalam koridor ragam tulis, secara umum dapat disampaikan bahwa semakin banyak dan semakin mutakhir kosakata yang digunakan dalam sebuah tulisan, makin tinggi pula tingkat penguasaan bahasa seseorang. Oleh karenanya, variasi kosakata sering menjadi salah satu standar penilaian kualitas tulisan di berbagai negara (Azodi, Karimi, \& Vaezi, 2014; White, 2014; Zhang, 2014). Selain itu, variasi kosakata juga dapat menjadi tolok ukur kemampuan seseorang berbahasa, baik dalam bahasa pertama maupun pada bahasa asing (Ratri, 2017). Ukuran variasi leksikal tradisional adalah rasio kata-kata yang berbeda (tipe) dengan jumlah total kata (token), yang disebut rasio token tipe, atau TTR (Bates, Bretherton, \& Snyder, 1991). TTR sendiri juga telah banyak digunakan dalam penelitian bahasa anak sebagai indeks keragaman leksikal (Richards, 1987).

Penelitian terkaitprofil kosakatatelah dilakukanAstika(2016)denganmenjelaskan profil kosakata yang digunakan dalam satu seri buku teks bahasa Inggris saat ini yang digunakan di SMP Indonesia. Profil keseluruhan menunjukkan bahwa cakupan kosakata dari kata-kata yang paling sering digunakan (K1 dan K2) adalah 92,65\%, menunjukkan bahwa itu di bawah tingkat yang diperlukan (95\%) untuk pemahaman yang mudah. Penelitian ini merekomendasikan untuk meningkatkan komprehensibilitas buku teks. Sementara Gregori-Signes \& Clavel-Arroitia (2015) melakukan penelitian dengan menganalisis kerapatan leksikal dan variasi leksikal dalam tulisan dari dua kelompok mahasiswa tahun pertama di Universitat de València pada awal dan akhir periode pengajaran satu semester. Penelitian ini mengklaim bahwa adalah mungkin untuk mendapatkan ukuran kekayaan leksikal yang stabil di dua bagian tulisan yang dihasilkan oleh pelajar yang sama. Hasil tulisan siswa menjadi bagian penting dalam penilaian kompetensi linguistik siswa. Dengan demikian, ukuran ini dapat menjadi instrumen pedagogi untuk mendeteksi siswa yang memiliki masalah karena kosakata yang 
buruk. Setelah masalah-masalah tersebut terdeteksi, akan lebih mudah bagi guru untuk membantu siswa mereka dalam penguasaan kosakata akademis dan frekuensi rendah.

Berdasarkan penelitian-penelitian yang disebutkan sebelumnya, dapat diketahui bahwa kualitas suatu teks dapat diukur dengan berbagai cara. Standar kualitas teks juga berbeda dalam setiap jenjang penulis atau sasaran pembacanya sehingga sesuai dengan hasil yang diharapkan. Teks dalam pendidikan atau akademik akan memiliki kriteria yang berbeda dengan teks non-akademik. Begitu juga teks untuk orang dewasa akan berbeda dengan teks untuk anak-anak. Namun penelitian yang terkait dengan kualitas teks untuk anak-anak cukup sulit ditemukan. Sedangkan memilih bahan bacaan untuk anak dengan kualitas yang baik adalah hal yang penting dalam pendidikan. Bahan bacaan untuk anak juga tidak terbatas pada pendidikan yang ditempuh di sekolah saja seperti buku-buku pelajaran tetapi juga bacaan-bacaan lain seperti buku cerita anak.

Bukubahan bacaan literasi cerita rakyatadalahbukubahan bacaanyang berisicerita rakyat dari provinsi di seluruh Indonesia yang berada di situs web resmi Kementerian Pendidikan dan Kebudayaan sebagai buku bahan bacaan literasi 2016. Pembuatan buku bahan bacaan literasi ini adalah bentuk dukungan Gerakan Literasi Nasional oleh Badan Pengembangan dan Pembinaan Bahasa Kementerian Pendidikan dan Kebudayaan. Buku-buku cerita rakyat tersebut adalah buku yang dipilih dan direkomendasikan oleh pemerintah yang berarti memiliki kualitas yang baik karena sesuai dengan tingkat kebutuhan pembacanya. Penelitian ini bertujuan untuk mengetahui profil kosakata dalam bahan bacaan literasi cerita rakyat tingkat SD di Pulau Jawa, Kalimantan, dan Sulawesi dengan mencari variasi leksikal serta melihat tingkat kemudahan pada buku cerita rakyat di masing-masing pulau. Selain itu, penelitian ini akan juga akan memaparkan persamaan dan perbedaan antara cerita rakyat di Pulau Jawa, Kalimantan, dan Sulawesi.

\section{METODOLOGI PENELITIAN}

Penelitian ini menggunakan metode kualitatif dengan memaparkan hasil analisis penelitian sejelas-jelasnya berdasarkan teori yang digunakan. Data yang digunakan adalah buku bahan bacaan literasi cerita rakyat tingkat SD yang diunduh di situs web resmi Kementrian Pendidikan dan Kebudayaan (2016). Buku yang dipilih adalah buku cerita rakyat yang hanya berasal dari Pulau Jawa, Kalimantan, dan Sulawesi. Buku cerita rakyat di Pulau Jawa ditemukan sebanyak 19 buku yang terdiri dari Pertarungan Sultan Maulana Hasanuddin, Sumur Keramat Jati Herang, Asal Usul Nama Kecamatan Bantul, Pangeran Purbaya dan Raksasa Jin Sepanjang, Petualangan Baron Sakender, Cerita Kisah Dewi Samboja, Dalem Boncel, Nyi Rengganis dan Taman Banjarsari, Si Buncir, Si Kabayan, Kain Tenun dan Putra Mahkota, Cerita Darman dan Darmin, Gatotkaca Satria dari Pringgadani, Pangeran Saputra, Banterang Surati, Cinta di Pulau Mandangin, Joko Dolog, Kesatria yang Rendah Hati, dan Jaka Prabangkara. Selanjutnya buku cerita rakyat di Pulau Kalimantan sebanyak 18 buku yang terdiri 
dari Asal Usul Burung Hantu, Raja Sinadin, Seri Genteng, Asal Mula Kotabaru, AsalUsul Nama Kampung Uka-Uka, Kisah Datu Diyang, Kisah Datu Pemberani, Legenda Telaga Alam Banyu Batuah, Bukit Batu Suli, Nyai Balau, Nyai Undang, Penunggu Sungai Kapuas, Aji Batara Agung, Kisah Si Pego, Puan dan Si Taddung, Burung Ajaib, Aki Balak, dan Putri Kumalasari. Sedangkan buku cerita rakyat di Pulau Sulawesi sebanyak 17 buku yang terdiri dari Panglima To Dilaling, Samba Paria, Tobara dari Bone Talondo, Tuing-Tuing dan Panci Emas, Vova Sanggayu, Dauppare, La Tadampareng Puang Rimanggalatung, Pangeran Barasa, Tiga Sekawan dan Posalia, Vulenggedingo, Vuyul Punsu Negunggun, Putri Waeruwondo, Raja Indra Pitara, Teladan Si Buи Buu, Ansuang Bekeng, Keke Panagian, dan Lumimuut. Berkas yang telah unduh harus diubah menjadi file txt agar bisa digunakan dalam software yang digunakan untuk penelitian yaitu AntWordProfiler dan AntConc.

Profil kosakata dilakukan dengan menggunakan software AntWordProfiler untuk mencari variasi leksikal dan tingkat kemudahan pada setiap pulau. Seluruh buku yang berasal dari satu pulau dimasukkan secara bersama dalam User File (s). Langkah selanjutnya adalah menghapus seluruh Level List(s) dan mengubahnya dengan kosakata umum bahasa Indonesia (Kwary, 2013)karena data yang digunakan adalah Bahasa Indonesia. Setelah itu berikan centang pada semua pilihan di bagian output setting lalu pilih start. Hasil dapat dilihat pada bagian Results terutama pada bagian Statistics. Variasi leksikal akan dihitung dengan rumus TTR dengan membagi tipe kata dengan token pada cerita rakyat di Pulau Jawa, Kalimantan, dan Sulawesi. Selanjutnya untuk mengetahui buku cerita rakyat yang lebih mudah dibaca, penelitian ini akan membandingkan token (\%) yang berada pada level 1 yaitu Indonesia High Frequency List atau kosakata umum bahasa Indonesia.

Selanjutnya untuk melihat persamaan dan perbedaan dari cerita rakyat di Pulau Jawa, Kalimantan dan Sulawesi adalah dengan melihat 30 daftar content words dengan frekuensi tertinggi dalam setiap pulau dengan range minimal 9 sehingga dapat diketahui kata-kata yang sering muncul dan tersebar dalam buku di masing-masing pulau. Data setiap pulau dimasukkan dalam software AntConc dengan memasukkan semua file txt di satu pulau pada bagian Corpus File dan memilih Word List pada menu dan menekan tombol Start. Selanjutnya daftar kata dengan frekuensi tertinggi akan muncul. Kata-kata yang dipilih dalam setiap pulau adalah 30 content words dengan frekuensi tertinggi dengan minimal range 9. Selanjutnya untuk mencari persamaan dalam setiap pulau dilakukan dengan memilih kata-kata yang selalu ada dalam setiap pulau, sedangkan untuk melihat perbedaannya dilakukan dengan memilih kata-kata yang hanya muncul di satu pulau saja. Kata-kata yang telah dipilih tersebut akan diklasifikasikan berdasarkan teori Newmark (1988) yang mengkategorikan lima kata yang mengandung unsur kebudayaan yaitu, ekologi, kebudayaan material (artefak), Kebudayaan sosial, organisasi, dan kebiasaan. Ekologi mencakup flora fauna, angin, 
cuaca, dan ekosistem. Kebudayaan material (artefak) mencakup jenis makanan, pakaian, bangunan, kawasan, dan perangkat transportasi. Kebudayaan sosial mencakup pekerjaan dan hiburan. Organisasi mencakup adat istiadat, konsep kepercayaan, aktivitas pemerintahan dan politik, serta artistik. Sedangkan kebiasaan atau sikap dan gerak gerik tubuh sehingga sering dijabarkan sebagai non-cultural language.

\section{HASIL DAN PEMBAHASAN}

\section{Variasi Leksikal dan Tingkat Kemudahan}

Untuk menjawab variasi leksikal dan tingkat kemudahan pada masing-masing buku cerita di setiap pulau, hasil statistik pada software AntWordProfiler adalah bagian yang penting untuk dilihat. Pada bagian ini, seluruh profil kosakata dalam data akan tergambar dengan jelas sehingga memudahkan dalam analisis penelitian. Untuk mengetahui variasi leksikalnya, perhatikan kolom bagian jumlah token dan tipe kata.

Tabel 1. Profil Kosakata Cerita Rakyat di Pulau Jawa

\begin{tabular}{llllll}
\hline LEVEL & FILE & TOKEN & $\begin{array}{l}\text { TOKEN } \\
\text { \% }\end{array}$ & TIPE & $\begin{array}{l}\text { T I P E } \\
\text { \% }\end{array}$ \\
\hline $\mathbf{1}$ & Kwary_ID_List1_Apr2013.txt & 80.588 & 57,44 & 1.593 & 15,31 \\
$\mathbf{0}$ & - & 59.700 & 42,56 & 88.14 & 84,69 \\
& TOTAL: & 140.288 & & 10.407 & \\
& & & & & \\
\hline
\end{tabular}

Dari tabel 1 dapat diketahui bahwa dalam seluruh buku cerita rakyat di Pulau Jawa yang terdiri dari 19 buku memiliki jumlah tipe sebanyak 10.407 dan token sebanyak 140.288. Jika dirinci, jumlah token dan tipe kata di masing-masing buku cerita rakyat di Pulau Jawa adalah sebagai berikut.

1. Buku cerita Pertarungan Sultan Maulana Hasanuddin memiliki jumlah tipe 1.667 dan jumlah token sebanyak 5.745.

2. Buku cerita Sumur Keramat Jati Herang memiliki jumlah tipe 1.801 dan jumlah token 6.717 .

3. Buku cerita Asal Usul Nama Kecamatan Bantul memiliki jumlah tipe 1.652 dan jumlah token 6.527.

4. Buku cerita Pangeran Purbaya dan Raksasa Jin Sepanjang memiliki jumlah tipe 1.937 dan jumlah token 7.720 .

5. Buku cerita Petualangan Baron Sakender memiliki jumlah tipe 2.399 dan jumlah token 13.797.

6. Buku cerita Cerita Kisah Dewi Samboja memiliki jumlah tipe 1.727 dan jumlah token 8.155.

7. Buku cerita Dalem Boncel memiliki jumlah tipe 1.584 dan jumlah token 6.120. 
8. Buku cerita Nyi Rengganis dan Taman Banjarsari memiliki jumlah tipe 2.090 dan jumlah token 8.381 .

9. Buku cerita Si Buncir memiliki jumlah tipe 1.675 dan jumlah token 6.288.

10. Buku cerita Si Kabayan memiliki jumlah tipe 2.059 dan jumlah token 8.379.

11. Buku cerita Kain Tenun dan Putra Mahkota memiliki jumlah tipe 1.388 dan jumlah token 5.007.

12. Buku cerita Cerita Darman dan Darmin memiliki jumlah tipe 1.493 dan jumlah token 5.314 .

13. Buku cerita Gatotkaca Satria dari Pringgadani memiliki jumlah tipe 1.317 dan jumlah token 4.356 .

14. Buku cerita Pangeran Saputra memiliki jumlah tipe 1.391 dan jumlah token 5.506.

15. Buku cerita Banterang Surati memiliki jumlah tipe 2.287 dan jumlah token 9.671.

16. Buku cerita Cinta di Pulau Mandangin memiliki jumlah tipe 1.474 dan jumlah token 7.510.

17. Buku cerita Joko Dolog memiliki jumlah tipe 2.013 dan jumlah token 7.130

18. Buku cerita Kesatria yang Rendah Hati memiliki jumlah tipe 2.093 dan jumlah token 11.678.

19. Buku cerita Jaka Prabangkara memiliki jumlah tipe 1.817 dan jumlah token 6.287.

Berdasarkan jumlah buku cerita rakyat di Pulau Jawa yang terdiri dari 19 buku cerita rakyat, maka rata-rata token setiap buku adalah 7.383,6 token. Sedangkan tipe kata dalam setiap buku bisa sangat berbeda antar bukunya. Untuk melihat variasi leksikal pada buku cerita rakyat di Pulau Jawa dilakukan dengan membagi jumlah tipe kata yaitu 10.407 dengan jumlah token sebesar 140.288 sehingga jumlah variasi leksikal pada buku cerita rakyat di Pulau Jawa adalah 0,074.

Tabel 2. Profil Kosakata Cerita Rakyat di Pulau Kalimantan

\begin{tabular}{lllllc}
\hline LEVEL & FILE & TOKEN & TOKEN \% & TIPE & TIPE \% \\
\hline $\mathbf{1}$ & Kwary_ID_List1_Apr2013.txt & 79.300 & 62,09 & 1.572 & 16,41 \\
\multirow{2}{*}{$\mathbf{n}$} & - & 48.423 & 37,91 & 8.010 & 83,59 \\
& TOTAL: & 127.723 & & 9.582 & \\
\hline
\end{tabular}

Berdasarkan tabel 2 dapat diketahui bahwa dalam seluruh buku cerita rakyat di Pulau Kalimantan yang terdiri dari 18 buku memiliki jumlah tipe sebanyak 9.582 dan token sebanyak 127.723. Berikut ini adalah rincian tipe dan token dalam setiap buku 
cerita rakyat di Kalimantan.

1. Buku cerita Asal Usul Burung Hantu memiliki jumlah tipe 1.908 dan jumlah token 7.942 .

2. Buku cerita Raja Sinadin memiliki jumlah tipe 1.593 dan jumlah token 6.107.

3. Buku cerita Seri Genteng memiliki jumlah tipe 1.923 dan jumlah token 7.050.

4. Buku cerita Asal Mula Kotabaru memiliki jumlah tipe 2.067 dan jumlah token 8.208 .

5. Buku cerita Asal-Usul Nama Kampung Uka-Uka memiliki jumlah tipe 1.536 dan jumlah token 5.698.

6. Buku cerita Kisah Datu Diyang memiliki jumlah tipe 1.935 dan jumlah token 7.569 .

7. Buku cerita Kisah Datu Pemberani memiliki jumlah tipe 1.654 dan jumlah token 5.930 .

8. Buku cerita Legenda Telaga Alam Banyu Batuah memiliki jumlah tipe 1.890 dan jumlah token 8.306.

9. Buku cerita Bukit Batu Suli memiliki jumlah tipe 1.450 dan jumlah token 7.648.

10. Buku cerita Nyai Balau memiliki jumlah tipe 1.899 dan jumlah token 7.832 .

11. Buku cerita Nyai Undang memiliki jumlah tipe 1.838 dan jumlah token 7.875 .

12. Buku cerita Penunggu Sungai Kapuas memiliki jumlah tipe 1.341 dan jumlah token 4.748

13. Buku cerita Aji Batara Agung memiliki jumlah tipe 1.936 dan jumlah token 8.378

14. Buku cerita Kisah Si Pego memiliki jumlah tipe 1.804 dan jumlah token 7.227.

15. Buku cerita Puan dan Si Taddung memiliki jumlah tipe 1.765 dan jumlah token 7.489 .

16. Buku cerita Burung Ajaib memiliki jumlah tipe 1.548 dan jumlah token 5.265.

17. Buku cerita Aki Balak memiliki jumlah tipe 2.094 dan jumlah token 9.007.

18. Buku cerita Putri Kumalasari memiliki jumlah tipe 1.352 dan jumlah token 5.444 .

Jika dilihat dari jumlah buku cerita rakyat di Pulau Kalimantan yang terdiri dari 18 buku cerita rakyat, setiap buku memiliki rata-rata 7.095,7 token dalam setiap bukunya. Untuk melihat variasi leksikal pada buku cerita rakyat di Pulau Kalimantan dilakukan dengan membagi jumlah tipe kata yaitu 9.582 dengan jumlah token sebesar 127.723 sehingga jumlah variasi leksikal pada buku cerita rakyat di Pulau Kalimantan adalah 0,075 . 
Tabel 3. Profil Kosakata Cerita Rakyat di Pulau Sulawesi

\begin{tabular}{llllll}
\hline LEVEL & FILE & TOKEN & TOKEN \% & TIPE & TIPE \% \\
\hline $\mathbf{1}$ & Kwary_ID_List1_Apr2013.txt & 75.363 & 61,58 & 1.514 & 16,51 \\
$\mathbf{0}$ & - & 47.014 & 38,42 & 7.658 & 83,49 \\
& TOTAL: & 122.377 & & 9.172 & \\
\hline
\end{tabular}

Tabel 3 menunjukkan bahwa dalam seluruh buku cerita rakyat di Pulau Sulawesi yang terdiri dari 17 buku memiliki jumlah tipe 9.172 dan jumlah token sebanyak 122.377. Berikut ini adalah rincian jumlah tipe dan token kata dalam setiap buku cerita rakyat di Pulau Sulawesi.

1. Buku cerita Panglima To Dilaling memiliki jumlah tipe 1.231 dan jumlah token 4.830 .

2. Buku cerita Samba Paria memiliki jumlah tipe 1.637 dan jumlah token 5.863 .

3. Buku cerita Tobara dari Bone Talondo memiliki jumlah tipe 1.627 dan jumlah token 6.525 .

4. Buku cerita Tuing-Tuing dan Panci Emas memiliki jumlah tipe 1.306 dan jumlah token 5.804.

5. Buku cerita Vova Sanggayu memiliki jumlah tipe 1.692 dan jumlah token 6.623.

6. Buku cerita Dauppare memiliki jumlah tipe 1.872 dan jumlah token 9.062.

7. Buku cerita La Tadampareng Puang Rimanggalatung memiliki jumlah tipe 2.147 dan jumlah token 8.040.

8. Buku cerita Pangeran Barasa memiliki jumlah tipe 1.758 dan jumlah token 7.248 .

9. Buku cerita Tiga Sekawan dan Posalia memiliki jumlah tipe 1.777 dan jumlah token 7.701.

10. Buku cerita Vulenggedingo memiliki jumlah jenis 1.622 dan jumlah token 6.166.

11. Buku cerita Vuyul Punsu Negunggun memiliki jumlah tipe 1.696 dan jumlah token 7.301.

12. Buku cerita Putri Waeruwondo memiliki jumlah tipe 2.065 dan jumlah token 8.161 .

13. Buku cerita Raja Indra Pitara memiliki jumlah tipe 2.043 dan jumlah token 9.061 .

14. Buku cerita Teladan Si Buи Buи memiliki jumlah tipe 1.579 dan jumlah token 7.814 .

15. Buku cerita Ansuang Bekeng memiliki jumlah tipe 1.747 dan jumlah token 6.179 . 
16. Buku cerita Keke Panagian memiliki jumlah tipe 1.892 dan jumlah token 9.222 .

17. Buku cerita Lumimuut memiliki jumlah tipe 1.831 dan jumlah token 6777.

Jika dilihat dari jumlah buku cerita rakyat di Pulau Sulawesi yang terdiri dari 17 buku cerita rakyat, maka rata-rata setiap buku memiliki 7.198,6 token dalam setiap bukunya. Variasi leksikal pada buku cerita rakyat di Pulau Sulawesi dilakukan dengan membagi jumlah tipe kata yaitu 9.172 dengan jumlah token sebesar 122.377sehingga jumlah variasi leksikal pada buku cerita rakyat di Pulau Sulawesi adalah 0,075.

Komponen leksikal adalah salah satu faktor penting dalam penilaian suatu teks (Engber, 1995). Seperti yang di sampaikan Johansson (2009) bahwa semakin bervariasi kosakata yang dimiliki suatu teks, semakin tinggi variasi leksikalnya. Agar leksikal teks menjadi sangat beragam, pembicara atau penulis harus menggunakan banyak kata yang berbeda, dengan sedikit pengulangan kata-kata yang sudah digunakan. Setelah mengetahui variasi leksikal dalam buku cerita rakyat di masing-masing pulau, dapat diketahui bahwa ketiganya memiliki variasi leksikal yang rendah. Variasi leksikal pada cerita rakyat di Pulau Jawa adalah 0,074 yang merupakan variasi leksikal yang paling sedikit dibandingkan cerita rakyat di Pulau Kalimantan dan Sulawesi yang sama-sama memiliki variasi leksikal sebesar 0,075. Cerita rakyat di Pulau Jawa menggunakan token dan tipe yang lebih besar dari pada cerita rakyat di Pulau Kalimantan dan Sulawesi. Namun, cerita rakyat Jawa menunjukkan variasi leksikal yang lebih kecil dari pada cerita rakyat Kalimantan dan Sulawesi. Hal ini menujukan bahwa cerita rakyat di Jawa lebih sering menggunakan kata yang berulang-ulang dan tidak lebih beragam daripada cerita rakyat di Kalimantan dan Sulawesi. Walaupun demikian selisih ketiganya tidak terlalu besar sehingga perbedaannya juga tidak terlalu signifikan. Selanjutnya hasil ini menunjukkan bahwa jumlah token yang banyak tidak selalu menunjukkan variasi leksikal yang tinggi seperti yang terjadi pada cerita rakyat di Pulau Jawa.

Berbeda dengan mencari variasi leksikal, tingkat kemudahan dapat dilihat dari token (\%) pada level 1 yang merupakan kosakata umum bahasa Indonesia atau high frequency word dari masing-masing pulau. Secara ringkas dapat kosakata umum bahasa Indonesia dalam buku cerita rakyat masing-masing pulau dapat dilihat di tabel 4 .

Tabel 4. Jumlah Token dalam Level 1

\begin{tabular}{lcl}
\hline Cerita Rakyat & Jumlah Token & Token (\%) \\
\hline Jawa & 140.288 & 57,44 \\
\hline Kalimantan & 127.723 & 62,09 \\
\hline Sulawesi & 122.377 & 61,58 \\
\hline
\end{tabular}

Tingkat kemudahan antar cerita rakyat dilakukan hanya melihat token pada level 1 karena yang harus diperhatikan adalah jumlah kosakata umumnya saja. Sedangkan level 0 terdiri dari kata-kata yang tidak termasuk dalam cakupan kosakata umum seperti 
nama, lokasi atau istilah-istilah yang spesifik. Kwary (2013) menyatakan bahwa semakin mudah teks, semakin tinggi cakupan daftar kosakata umumnya. Dengan demikian buku cerita rakyat di Pulau Kalimantan paling mudah dibaca karena mengandung kosakata umum Bahasa Indonesia yang lebih banyak yaitu 62,09 \% dari pada buku cerita anak di Pulau Jawa dan Sulawesi. Posisi kedua ditempati oleh cerita rakyat di Pulau Sulawesi dengan token $61,58 \%$ dan cerita rakyat di Pulau Jawa menempati posisi paling sulit dibaca jika dibandingkan cerita rakyat lainnya dengan token 57,44 \%.

\section{Persamaan dan Perbedaan}

Cerita rakyat dibuat oleh dan untuk masyarakat itu sendiri, maka cerita rakyat dapat menggambarkan keinginan, harapan, dan angan-angan dari masyarakat tersebut. Berbeda daerah cerita rakyat, tentu nilai-nilai yang dimunculkan juga berbeda sehingga memperlihatkan budaya berbeda. Dengan demikian cerita rakyat daerah tertentu akan memperlihatkan budaya tertentu. Oleh karena itu cerita rakyat yang berasal dari Pulau Jawa tentu saja akan memiliki beberapa hal yang berbeda dengan cerita rakyat di Pulau Kalimantan dan Sulawesi. Untuk melihat persamaan dan perbedaan tersebut, penelitian ini akan melihat dari 30 content words dengan frekuensi tertinggi yang memiliki range diatas 9 di masing-masing cerita rakyat. Berikut adalah data yang diperoleh di masingmasing pulau.

Tabel 5. Content Words dengan Frekuesi Tertinggi di Pulau Jawa

\begin{tabular}{llllllllll}
\hline No. & Rank & Freq. & Range & Words & No. & Rank & Freq. & Range & Words \\
\hline $\mathbf{1}$ & 11 & 998 & 15 & raja & $\mathbf{1 6}$ & 59 & 287 & 17 & hutan \\
$\mathbf{2}$ & 19 & 535 & 19 & ada & $\mathbf{1 7}$ & 61 & 287 & 19 & melihat \\
$\mathbf{3}$ & 20 & 531 & 19 & orang & $\mathbf{1 8}$ & 62 & 286 & 19 & bahasa \\
$\mathbf{4}$ & 21 & 500 & 15 & putri & $\mathbf{1 9}$ & 64 & 284 & 19 & baik \\
$\mathbf{5}$ & 26 & 442 & 16 & kerajaan & $\mathbf{2 0}$ & 65 & 283 & 19 & tiba \\
$\mathbf{6}$ & 29 & 402 & 19 & dapat & $\mathbf{2 1}$ & 70 & 270 & 19 & sastra \\
$\mathbf{7}$ & 30 & 398 & 19 & anak & $\mathbf{2 2}$ & 77 & 256 & 11 & prajurit \\
$\mathbf{8}$ & 35 & 372 & 19 & kata & $\mathbf{2 3}$ & 80 & 251 & 14 & istana \\
$\mathbf{9}$ & 36 & 369 & 19 & hari & $\mathbf{2 4}$ & 82 & 245 & 19 & tempat \\
$\mathbf{1 0}$ & 38 & 365 & 19 & seorang & $\mathbf{2 5}$ & 83 & 244 & 15 & ibu \\
$\mathbf{1 1}$ & 39 & 357 & 19 & menjadi & $\mathbf{2 6}$ & 85 & 241 & 19 & rakyat \\
$\mathbf{1 2}$ & 40 & 352 & 14 & hamba & $\mathbf{2 7}$ & 88 & 239 & 16 & rumah \\
$\mathbf{1 3}$ & 51 & 302 & 19 & cerita & $\mathbf{2 8}$ & 90 & 230 & 10 & paduka \\
$\mathbf{1 4}$ & 52 & 300 & 19 & kembali & $\mathbf{2 9}$ & 92 & 221 & 19 & jawab \\
$\mathbf{1 5}$ & 57 & 293 & 19 & hati & $\mathbf{3 0}$ & 94 & 219 & 18 & tanya \\
\hline
\end{tabular}


Intan Amalia

Tabel 6. Content Words dengan Frekuesi Tertinggi di Pulau Kalimantan

\begin{tabular}{llllllllll}
\hline No. & Rank & Freq. & Range & Words & No. & Rank & Freq. & Range & Words \\
\hline $\mathbf{1}$ & 15 & 656 & 18 & ada & $\mathbf{1 6}$ & 49 & 282 & 16 & bisa \\
$\mathbf{2}$ & 18 & 655 & 11 & raja & $\mathbf{1 7}$ & 53 & 273 & 14 & kampung \\
$\mathbf{3}$ & 19 & 609 & 18 & orang & $\mathbf{1 8}$ & 56 & 270 & 18 & sastra \\
$\mathbf{4}$ & 20 & 600 & 18 & anak & $\mathbf{1 9}$ & 67 & 244 & 18 & baik \\
$\mathbf{5}$ & 21 & 547 & 16 & ibu & $\mathbf{2 0}$ & 68 & 241 & 18 & melihat \\
$\mathbf{6}$ & 22 & 536 & 18 & kata & $\mathbf{2 1}$ & 71 & 238 & 18 & besar \\
$\mathbf{7}$ & 30 & 425 & 18 & dapat & $\mathbf{2 2}$ & 72 & 232 & 18 & tempat \\
$\mathbf{8}$ & 34 & 378 & 18 & menjadi & $\mathbf{2 3}$ & 74 & 229 & 18 & banyak \\
$\mathbf{9}$ & 37 & 363 & 18 & hari & $\mathbf{2 4}$ & 75 & 228 & 18 & kehidupan \\
$\mathbf{1 0}$ & 39 & 346 & 14 & burung & $\mathbf{2 5}$ & 76 & 227 & 18 & rakyat \\
$\mathbf{1 1}$ & 41 & 329 & 16 & rumah & $\mathbf{2 6}$ & 78 & 219 & 14 & ayah \\
$\mathbf{1 2}$ & 44 & 299 & 18 & air & $\mathbf{2 7}$ & 79 & 218 & 18 & bahasa \\
$\mathbf{1 3}$ & 46 & 290 & 18 & seorang & $\mathbf{2 8}$ & 81 & 217 & 18 & manusia \\
\hline $\mathbf{1 4}$ & 47 & 288 & 18 & cerita & $\mathbf{2 9}$ & 83 & 215 & 14 & sungai \\
$\mathbf{1 5}$ & 48 & 284 & 18 & kembali & $\mathbf{3 0}$ & 85 & 214 & 12 & kerajaan \\
\hline
\end{tabular}

Tabel 7. Content Words dengan Frekuesi Tertinggi di Pulau Sulawesi

\begin{tabular}{llllllllll}
\hline No. & Rank & Freq. & Range & Words & No. & Rank & Freq. & Range & Words \\
\hline $\mathbf{1}$ & 9 & 946 & 13 & raja & $\mathbf{1 6}$ & 49 & 291 & 17 & hari \\
$\mathbf{2}$ & 19 & 548 & 17 & ada & $\mathbf{1 7}$ & 50 & 291 & 17 & sastra \\
$\mathbf{3}$ & 17 & 572 & 17 & orang & $\mathbf{1 8}$ & 52 & 284 & 17 & bahasa \\
$\mathbf{4}$ & 23 & 510 & 17 & anak & $\mathbf{1 9}$ & 56 & 275 & 17 & cerita \\
$\mathbf{5}$ & 28 & 465 & 17 & kata & $\mathbf{2 0}$ & 57 & 274 & 17 & baik \\
$\mathbf{6}$ & 31 & 429 & 11 & kerajaan & $\mathbf{2 1}$ & 60 & 267 & 16 & bisa \\
$\mathbf{7}$ & 32 & 423 & 9 & putri & $\mathbf{2 2}$ & 62 & 265 & 17 & melihat \\
$\mathbf{8}$ & 35 & 391 & 12 & ibu & $\mathbf{2 3}$ & 64 & 263 & 17 & kembali \\
$\mathbf{9}$ & 36 & 383 & 12 & burung & $\mathbf{2 4}$ & 69 & 239 & 17 & rakyat \\
\hline $\mathbf{1 0}$ & 37 & 379 & 17 & dapat & $\mathbf{2 5}$ & 77 & 215 & 17 & tempat \\
$\mathbf{1 1}$ & 39 & 336 & 16 & rumah & $\mathbf{2 6}$ & 81 & 202 & 14 & ikan \\
$\mathbf{1 2}$ & 42 & 320 & 12 & istana & $\mathbf{2 7}$ & 86 & 196 & 17 & mencari \\
$\mathbf{1 3}$ & 44 & 311 & 17 & seorang & $\mathbf{2 8}$ & 88 & 195 & 17 & hati \\
\hline $\mathbf{1 4}$ & 46 & 308 & 17 & menjadi & $\mathbf{2 9}$ & 93 & 186 & 12 & laut \\
$\mathbf{1 5}$ & 47 & 305 & 16 & tiba & $\mathbf{3 0}$ & 94 & 183 & 17 & air \\
\hline
\end{tabular}

Untuk melihat persamaan dalam cerita rakyat di Pulau Jawa, Kalimantan, dan Sulawesi dilakukan dengan melihat kata yang selalu ada di dalam setiap cerita. Katakata tersebut adalah Ada, anak, bahasa, baik, cerita, dapat, hari, ibu, kata, kembali, kerajaan, melihat, menjadi, orang, raja, rakyat, rumah, sastra, seseorang, dan tempat. Terdapat beberapa aspek yang menonjol dari kata-kata yang ditemukan di ketiga cerita rakyat. Misalnya saja kata raja memiliki frekuensi yang tinggi dan range yang tinggi pula sehingga memperlihatkan bahwa walaupun tokoh raja tidak selalu menjadi 
tokoh utama dalam cerita, tokoh raja adalah tokoh yang berpengaruh dalam semua cerita rakyat. Latar kerajaan adalah hal yang biasa disebutkan dalam sebagian besar cerita rakyat. Begitu juga dengan kata rakyat juga memiliki frekuensi yang tinggi dan disebutkan dalam semua cerita. Dengan demikian kisah dengan latar kerajaan sehingga adanya tokoh raja dan rakyat adalah hal yang biasa dalam cerita rakyat di Pulau Jawa, Kalimantan, dan Sulawesi. Hal ini mungkin mencerminkan kehidupan di Indonesia yang dulunya memiliki banyak kerajaan yang tersebar di seluruh Indonesia termasuk di Jawa, Kalimantan, dan Sulawesi. Bahkan prasasti tertua di Kalimantan timur yang ditulis dalam huruf Pallawa yang digunakan di India Selatan pada tahun 400 M, menginformasikan tentang keberadaan Kerajaan Kutai dengan rajanya Mulawarman beserta dengan upacara ritual yang diadakan di kerajaan tersebut (Poerbatjaraka, 1952). Selain itu terlihat bahwa satuan waktu yang digunakan dalam cerita rakyat di Pulau Jawa, Kalimantan, Sulawesi adalah hari. Beberapa cerita juga menyebutkan satuan waktu dengantahun, tetapimemiliki frekuensiyang sedikitsekalijikadibandingkandenganhari.

Selain itu berdasarkan data yang ditemukan terlihat bahwa hubungan keluarga yang selalu ada dalam setiap cerita adalah ibu dan anak. Dalam cerita rakyat sosok ibu adalah sosok yang penting dalam hampir di semua cerita. Begitu juga dengan sosok anak. Beberapa cerita menyebutkan anak sebagai tokoh penting bahkan utama sehingga muncul dalam semua cerita rakyat dari ketiga pulau. Selain itu sering juga ditemukan adanya interaksi di antara ibu dan anak walaupun juga terdapat sosok ayah yang muncul di beberapa cerita. Namun demikian hal ini menunjukkan bahwa hubungan antara ibu dan anak adalah hal yang penting dalam kehidupan cerita sehingga terlihat paling menonjol. Hubungan antara ibu dan anak adalah hal yang mungkin dianggap sangat istimewa dibandingkan hubungan-hubungan lain dalam keluarga.

Untuk melihat perbedaan dalam setiap cerita rakyat di antara Pulau Jawa, Kalimantan, dan Sulawesi, penelitian ini akan melihat kata-kata yang hanya disebutkan di satu pulau di antara 30 kata yang dipilih. Kata-kata yang termasuk kriteria ini dalam cerita rakyat di Pulau Jawa adalah hamba, hutan, jawab, paduka, prajurit, dan tanya. Kata-kata yang hanya ditemukan di cerita rakyat Kalimantan adalah ayah, banyak, besar, kampung, kehidupan, manusia, dan sungai. Sedangkan kata-kata yang hanya disebutkan di cerita rakyat Sulawesi adalah ikan, laut dan mencari. Kata-kata ini akan dibagi sesuai dengan kategori yang dikemukakan oleh Newmark (1988) yaitu ekologi, kebudayaan material (artefak), Kebudayaan sosial, organisasi, dan kebiasaan. Berikut adalah kata-kata yang dapat diklasifikasikan.

Tabel 8. Klasifikasi Kata dengan Teori Newmark (1998)

\begin{tabular}{|l|l|l|l|}
\hline & Jawa & Kalimantan & Sulawesi \\
\hline Ekologi & Hutan & Sungai & $\begin{array}{l}\text { Ikan } \\
\text { Laut }\end{array}$ \\
\hline Kebudayaan Material & - & Kampung & - \\
\hline Kebudayaan Sosial & $\begin{array}{l}\text { Paduka } \\
\text { Prajurit }\end{array}$ & - & - \\
\hline
\end{tabular}


Kategori ekologi mencakup flora fauna, angin, cuaca, dan ekosistem. Dalam cerita rakyat yang termasuk kategori ini hanyalah hutan. Berdasarkan cerita rakyat Jawa banyak sekali aktivitas yang dapat dilakukan di dalam hutan seperti menjelajah, tinggal, berburu, bertemu sesuatu atau seseorang, dan lainnya. Ini menunjukkan kondisi geografis Jawa pada jaman dahulu yang memiliki banyak sekali ekosistem hutan sehingga latar kejadian dalam cerita rakyat juga banyak menggunakan hutan. Selain ekologi, cerita rakyat di Pulau Jawa sangat menunjukkan kebudayaan sosialnya yang mencakup pekerjaan dan hiburan. Hal ini terlihat dari kata paduka dan prajurit. Kata paduka ini merupakan kata yang melekat dengan orang-orang yang memiliki kekuasaan seperti raja. Selain itu pekerjaan yang hanya muncul di cerita rakyat Jawa adalah prajurit. Bagi masyarakat Jawa, jenis pekerjaan, gelar, atau julukan adalah hal yang diperhatikan dalam kehidupan sehari-hari. Dalam beberapa buku cerita rakyat Jawa bahkan menyebutkan beberapa istilah seperti raden dan jaka untuk menunjukkan kelas sosialnya. Selain itu kata hamba yang biasa digunakan oleh orang dengan kelas yang lebih rendah juga merupakan kata dengan frekuensi tertinggi dan memiliki range yang tersebar menunjukkan bahwa dalam cerita rakyat di Pulau Jawa memiliki sistem hierarki yang kuat dalam kehidupan sehari-hari. Dalam pemikiran Jawa orang-orang yang lebih tua, guru-guru, teristimewa orang-orang tua dan pimpinan adalah pokok penghormatan dan pemujaan, suatu kedudukan yang layak mereka dapatkan sebab mereka telah merawat, melindungi, dan mengajar anak-anak mereka (Mulder, 2001).

Ekologi yang ditonjolkan dalam cerita rakyat Kalimantan adalah sungai. Berdasarkan geografis di Kalimantan, jumlah sungai-sungai yang ada ada di Pulau ini sangat banyak. Sugeng (2013) menyebutkan bahwa tiga sungai terpanjang di Indonesia berada di Pulau Kalimantan yaitu, sungai Kapuas (1.143 km), sungai Mahakam $(920 \mathrm{~km})$, dan sungai Barito $(909 \mathrm{~km})$. Banyaknya sungai ini membuat masyarakat bergantung pada sungai dalam aktivitas sehari-hari. Masyarakat dapat membangun tempat tinggal bahkan terkenal dengan perkampungan yang bersusut dan berderet-deret. Selain itu, karena banyaknya sungai di Kalimantan ini juga menyebabkan banyaknya jalur transportasi melalui air. Begitu juga dalam cerita rakyat di Pulau Kalimantan menyebutkan beberapa aktivitas yang dapat dilakukan di sungai seperti mandi, berburu ikan, menjelajah, bermain dan sebagainya. Sementara kebudayaan material yang ditonjolkan dalam cerita rakyat Kalimantan adalah kampung yang merupakan tempat tinggal atau sejenis desa bagi masyarakat awam. Sebagian besar cerita rakyat di Pulau Kalimantan mengambil latar kampung sebagai pusat aktivitas masyarakat dalam cerita. Hal ini menunjukkan bahwa cerita rakyat yang berkembang di Kalimantan lebih menceritakan kehidupan di luar kerajaan dan terkait dengan masyarakat biasa.

Cerita rakyat di Pulau Sulawesi secara khusus hanya menonjolkan bagian ekologinya yang terdiri dari ekosistem yaitu laut dan fauna yaitu ikan. Banyak daerah- 
daerah Sulawesi yang terkenal dengan baharinya. Hestiyanto (2007) menjelaskan bahwa di perairan Indonesia arus laut yang membawa massa air dari Samudra Pasifik masuk dari Laut Sulawesi sebelum ke Selat Makassar. Mungkin ini salah satu menyebabkan Laut Sulawesi memiliki banyak spesies ikan termasuk ikan paus, lumba-lumba, kurakura laut dan berbagai makhluk bawah air lainnya. Hal ini dapat menjelaskan ekologi yang menonjol di cerita rakyat Sulawesi adalah laut dan ikan. Beberapa cerita rakyat menggunakan latar laut untuk melakukan beberapa aktivitas seperti memancing atau menangkap ikan. Diantara 17 cerita rakyat di Pulau Sulawesi, 12 diantaranya menggunakan kata laut, bahkan ada juga cerita rakyat yang menggunakan latar utama cerita dengan laut. Walaupun memiliki frekuensi yang tidak terlalu tinggi, jenis pekerjaan di laut juga disebutkan dalam cerita seperti nelayan. Dengan demikian cerita rakyat di Pulau Sulawesi secara khusus lebih menunjukkan ekologi yang dimilikinya yaitu laut karena ekositem ini sering terkait dengan aktivitas masyarakat dan ikan sebagai fauna yang mudah ditemukan dalam kehidupan sehari-hari masyarakat Sulawesi.

\section{KESIMPULAN}

Buku bahan bacaan literasi cerita rakyat tingkat SD yang direkomendasikan oleh pemerintah ini sesuai dengan tingkat kemampuan berbahasa pembacanya. Buku cerita rakyat di Pulau Jawa, Kalimantan dan Sulawesi memiliki variasi leksikal yang rendah karena menggunakan kata yang berulang-ulang dan tidak beragam. Variasi leksikal pada cerita rakyat di Pulau Jawa adalah 0,074 yang merupakan variasi leksikal yang paling sedikit dibandingkan cerita rakyat di Pulau Kalimantan dan Sulawesi yang memiliki variasi leksikal sebesar 0,075. Buku cerita rakyat di Pulau Kalimantan adalah buku yang paling mudah dibaca karena mengandung kosakata umum Bahasa Indonesia yang lebih banyak yaitu 62,09 \% dari pada buku cerita anak di Pulau Jawa dan Sulawesi. Secara umum cerita rakyat di Pulau Jawa, Kalimantan, dan Sulawesi menggunakan tokoh raja dan rakyat sebagai tokoh yang berpengaruh dalam semua cerita rakyat dengan latar kerajaan dan satuan waktu yang paling sering digunakan adalah hari. Cerita rakyat di Pulau Jawa secara khusus menunjukkan ekologi hutan sebagai tempat yang dapat melakukan berbagai aktivitas. Cerita rakyat di Pulau Jawa juga secara khusus sangat menunjukkan kebudayaan sosialnya yang mencakup pekerjaan dan hiburan. Bagi masyarakat Jawa, jenis pekerjaan, gelar, atau julukan adalah hal yang diperhatikan dalam kehidupan sehari-hari. Cerita rakyat di Pulau Kalimantan secara khusus menonjolkan ekologi sungai. Banyaknya sungai ini membuat masyarakat bergantung pada sungai dalam aktivitas sehari-hari. Sementara kebudayaan material yang ditonjolkan dalam cerita rakyat Kalimantan adalah kampung karena lebih menceritakan kehidupan diluar kerajaan dan terkait dengan masyarakat biasa. Sementara cerita rakyat di Pulau Sulawesi secara khusus lebih menunjukkan ekologi yang dimilikinya yaitu laut karena ekosistem ini sering terkait dengan aktivitas masyarakat. Sedangkan ikan sebagai fauna yang mudah ditemukan dalam kehidupan 
sehari-hari masyarakat Sulawesi.

\section{REFERENSI}

Astika, G. (2016). Profiling Vocabulary of English Textbooks for Indonesian Junior High Schools Using Vocabulary Profiler: A Fast Track to Improve Students'vocabulary Knowledge. IJOLTL: Indonesian Journal of Language Teaching and Linguistics , 1 (3), 203-218.

Azodi, N., Karimi, F., \& Vaezi, R. (2014). Measuring the Lexical Richness of Productive Vocabulary in Iranian EFL University Students' Writing Performance. Theory and Practice in Language Studies , 4 (9), 1837-1849.

Bates, E., Bretherton, I., \& Snyder, L. (1991). From First Words to Grammar: Individual Differences and Dissociable Mechanisms. Cambridge: Cambridge University Press.

Cahyaningrum, E. S., Cholimah, N., \& Christianti, M. (2014). Pelatihan Pengenalan Karakter untuk Anak Usia Dini melalui Cerita Rakyat Budaya Lokal Bagi Pendidik PAUD Non Formal TPA/KB/SPS se-Kecamatan Sleman. Jurnal Pendidikan Anak, 3 (1).

Dalwiningsih. (2017). Analisis Terjemahan Istilah Budaya pada Cerita Rakyat Jawa Timur. Surabaya: Airlangga University Press .

Danandjaja, J. (2007). Folklor Indonesia: Ilmu Gosip, Dongeng, dan lain-lain. Jakarta: Grafiti Pers.

Engber, C. A. (1995). The relationship of lexical proficiency to the quality of ESL compositions. Journal of second language writing , 4 (2), 139-155.

Gregori-Signes, C., \& Clavel-Arroitia, B. (2015). Analysing Lexical Density and Lexical Diversity in University Students' Written Discourse. Procedia-Social and Behavioral Sciences , 198, 546 - 556.

Hestiyanto, Y. (2007). Geografi SMA kelas X. Yudhistira Ghalia Indonesia.

Johansson, V. (2009). Lexical Diversity and Lexical Density in Speech and Writing: A Developmental Perspective. Working Papers in Linguistics , 53, 61-79.

Kementrian Pendidikan dan Kebudayaan. (2016). Diambil 21 Maret 2018, dari http:// badanbahasa.kemdikbud.go.id/lamanbahasa/statik/2234

Kwary, D. A. (2013). Creating and Testing the Indonesiaan High Frequency Word List. Jurnal KOLITA XI .

Kwary, D. A. (2013). The Indonesia High Frequency Word List . Diambil 20 Maret 2018, dari http://www.kwary.net/iwl.html

Mulder, N. (2001). Ruang Batin Masyarakat Indonesia . Yogyakarta : Lkis. 
Mustakim, M. N. (2005). Peranan Cerita dalam pembentukan Perkembangan anak TK. Jakarta: Depdiknas.

Nation, I. S. (2001). Learning Vocabulary in Another Language. UK: Cambridge University Press.

Newmark, P. (1988). A Textbook of Translation. UK: Prentice Hall.

Poerbatjaraka. (1952). Riwajat Indonesia. Jakarta: Jajasan Pembangunan.

Ratri, D. (2017). Analisis Kualitas Terjemahan dan Variasi Kosakata Abstrak Tesis Bahasa Indonesia dan Bahasa Inggris Program Magister Universitas Airlangga. Surabaya: Airlangga University Press.

Rhubido, D. (2017). Kosakata Akademik dan Kosakata Khusus Bahasa Indonesia: Pendekatan Linguistik Korpus. Surabaya: Airlangga University Press.

Richards, B. (1987). Type/token ratios: What do they really tell us? Journal of child language, 14 (2), 201-209.

Sugeng, H. R. (2013). The Amazing of Indonesia: 71 Keajaiban Indonesian yang Wajib Diketahui. Jakarta: Anak Kita.

White, R. H. (2014). Lexical Richness in Adolescent Writing, Insights from the Classroom: An L1 Vocabulary Development Study. Wellington: Victoria University of Wellington.

Zhang, Y. (2014). A Corpus Based Analysis of Lexical Richness of Beijing Mandarin Speaker: Variable Identification and Model Construction. Language Sciences , 44, 60-69. 